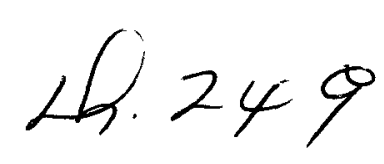

ARI-RP-38

7th/8th Quarterly Technical Progress Report

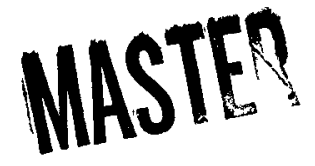

On

CHARACTERIZATION OF OPEN-CYCLE, COAL-FIRED MHD GENERATORS

RECEIVED EY TIO WUV 8 10.6

By

C.E. Kolb, J.B. Elgin, J. Wormhoudt, V. Yousefian, M. Martinez-Sanchez, and D. Dvore

Aerodyne Research, Inc.

Bedford Research Park, Crosby Drive

Bedford, MA 01730

Prepared Under ERDA Contract No. EX-76-C-01-2478

Period Covered: January 1 to June 30, 1978

\title{
Submitted to
}

Division of Magnetohydrodynamics

U.S. Department of Energy

July 1978

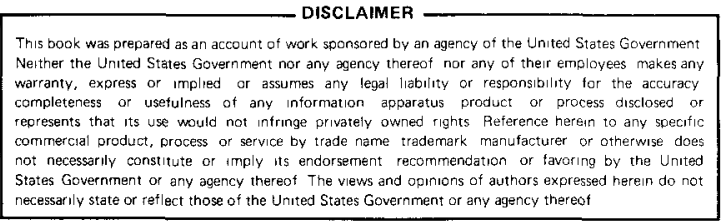




\section{DISCLAIMER}

This report was prepared as an account of work sponsored by an agency of the United States Government. Neither the United States Government nor any agency Thereof, nor any of their employees, makes any warranty, express or implied, or assumes any legal liability or responsibility for the accuracy, completeness, or usefulness of any information, apparatus, product, or process disclosed, or represents that its use would not infringe privately owned rights. Reference herein to any specific commercial product, process, or service by trade name, trademark, manufacturer, or otherwise does not necessarily constitute or imply its endorsement, recommendation, or favoring by the United States Government or any agency thereof. The views and opinions of authors expressed herein do not necessarily state or reflect those of the United States Government or any agency thereof. 


\section{DISCLAIMER}

Portions of this document may be illegible in electronic image products. Images are produced from the best available original document. 


\section{NOTICE}

This report was propared as an account of work sponsored by the United States Government Neither the United States nor the United States Department of Energy, nor any of their amployees, makes any warranty, express or implied, or assumes any legal liability or responsibility for the accuracy, completeness, or usefulness of any information, apparatus, product, or process disclosed, or represents that its use would not infringe privately owned rights Reference herein to any specific commercial product, process, or service by trade name, mark. manufacturer, or otherwise, does not necessartly constitute or imply its endorsement, recommendation, or favoring by the United States Government or any agency thereof The views and opinions of authors expressed herein do not necessarily state or reflect those of the United States Government or any agency thereof

Available from:

National Technical Information Service (NTIS)

U.S. Department of Commerce

5285 Port Royal Road

Sprirgfield, Virginia 22161

Price: Printed copy:

Microfiche: $\$ 3.00$ 
ABSTRACT

1.

INTRODUCTION. ........................ 1

2.

TECHNICAL PROGRESS SUMMARY . . . . . . . . . . 1

3. MODELING OF CORE FLOW PLASMA CHEMICAI

EFFECTS ON CONDUCTIVITY AND SEED RECOVERY . . . 5

3.1 Goals and Milestones ................

3. 2 Summary of Improvements to PACKAGE Code ...... 5

3.3 Work Forecast . . . . . . . . . . . . . . . 9

4. LABORATORY MEASUREMENTS AND THE DESIGN OF

A FIELD SCALE MASS SPECTROMETRIC PROBE . . . . . . 11

4.1 Goals and Milestones ................... 11

4. 2 Technical Progress on Laboratory Measurements . . . . . 13

4.3 Work Forecast .....................

5. MODELING OF ELECTRODE BOUNDARY LAYER

PLASMA DYNAMICS ................... 17

5.1 Goals and Milestones .................

5. 2 An Assessment of Past Work on MHD Plasma-Wall

Interaction ....................... 18

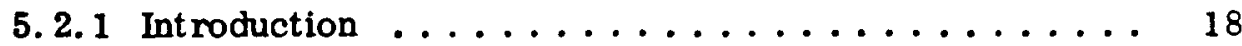

5. 2.2 Experimental Studies of MHD Arcs . . . . . . . . 19

5. 2. 3 Modeling of Diffuse and Arcing Discharges . . . . . . 22

5. 2. 4 Discussion of Previous Models . . . . . . . . . . .

5. 3 Technical Progress of Model Development......... 24

5.4 Work Forecast ................... 26 


\begin{abstract}
The successful design of full-scale open-cycle, coal-fired MHD generators for baseload electrical production requires a detailed understanding of the plasma chemical and plasma dynamic characteristics of anticipated combustor and channel fluids.
\end{abstract}

This report documents progress in efforts to model negative ion formation and slag condensation effects on core flow conductivity, to improve the ability to sample and characterize laboratory produced coal combustion plasmas, and to define a mathematical model of the diffuse discharge plasma sheath in the anode boundary layer. 


\section{INTRODUCTION}

The contract modification to Aerodyne Research, Inc. for further study on the Characterization of Open-Cycle, Coal-Fired MHD Generators has three general goals. The first two goals are extensions of the work performed during the initial phase of the con tract; they involve modeling plasma chemical effects on the core flow conductivity and efficiency of seed recovery and verifying the results of the computer model by first measuring coal plasma compositions in a laboratory burner, and then designing a full-scale, mass spectrometric probe to characterize the plasma flow from demonstration scale MHD combustors and generators.

The third goal of this work is to obtain a detailed understanding of the plasma and electro-chemical effects responsible for MHD electrode degradations. This anderstanding is to be quantified by computer modeling of the events at the electrode surface and in the electrode/plasma boundary layer under both diffuse and arcing discharge conditions.

These three contract tasks: 1) Modeling of Core Flow Plasma Chemical Effects on Conductivity and Seed Recovery; 2) Core Flow Model Validation by Laboratory Measurements and the Design of a Field Scale Mass Spectrometric Probe, and 3) Modeling of Electrode Boundary Layer Plasma Dynamics, are to be performed by December, 1979.

This report contains technical discussions involving upgrading of the PACKAGE code under Task 1, improvements to the laboratory coal plasma combustor and mass spectrometric sampling system under Task 2, and initial progress on a model of the anode plasma sheath model under Task 3 . Since procurement delays prevented work on the contract extension before late March, this report combines progress achieved during the seventh (Jan-Mar.) and eighth (Apr. -June) quarters of effort. 


\section{TECHNICAL PROGRESS SUMMARY}

A summary of progress achieved since work resumed in late March is shown below for each of the tasks represented in the extended contract effort. A projection of the time-phasing for the subtasks within each of the three tasks is shown in Figure 1.

Task 1 - Modeling of Core Flow Plasma Chemical Effects on Conductivity and Seed Recovery

A model has been developed to formulate and calculate the properties of the combustion products in a two-stage combustor. The model is programmed into the PACKAGE code. The calculations yield the properties of the combustion products of the first combustor, before and after removing a fraction of the cond nsed species, and the properties of combustion products in the second combustor after the addition of the extra oxidizer.

Task 2 - Core Flow Model Validation by Labo ratory Measurements and Design of a Field Scale Mass Spectrometric Probe

Section 4 presents the two general goals of the laboratory measurements program, support of MHD generator modeling and support of the design of a field-scale mass spectrometric probe. It then outlines a number of experimental objectives, explains how they contribute to the general goals, and outlines the improvements to the laboratory apparatus needed to accomplish them. Examples of improvements made during the reporting period are a modification of the burner allowing it to reach higher temperatures and the beginning of use of added chemicals to identify flame ions. The planning and construction of a gas handling system to quantitatively feed these chemicals, as well as of a sodium line reversal temperature measurement system are in progress. 
Task 1

Task 2

Task 3

d

\section{Subtask}

1A Conductivity Calculations

1B Alkali Seed Calculations

1C Slag Condensation Experiment

1D Slag Condensation Modeling

1E Radiation Heat Loss Assessment

24 Lab Burner Mcasurcments

2B Ficld Facility Assessment

2C Full Scale Probe Design

3A Electrode Heat Transfer Analysis

3B Electrode Surface Chemistry Analysis

3C Plasma Sheath Analysis

3D Boundary Layer Chemistry Analysis

3E Boundary Layer Flow Analysis

$3 F \quad$ Integrated Electrode Boundary I ayer Model

(a) With Present Slag Condensation Model

(1)) With Upgraded Slag Condensation Model

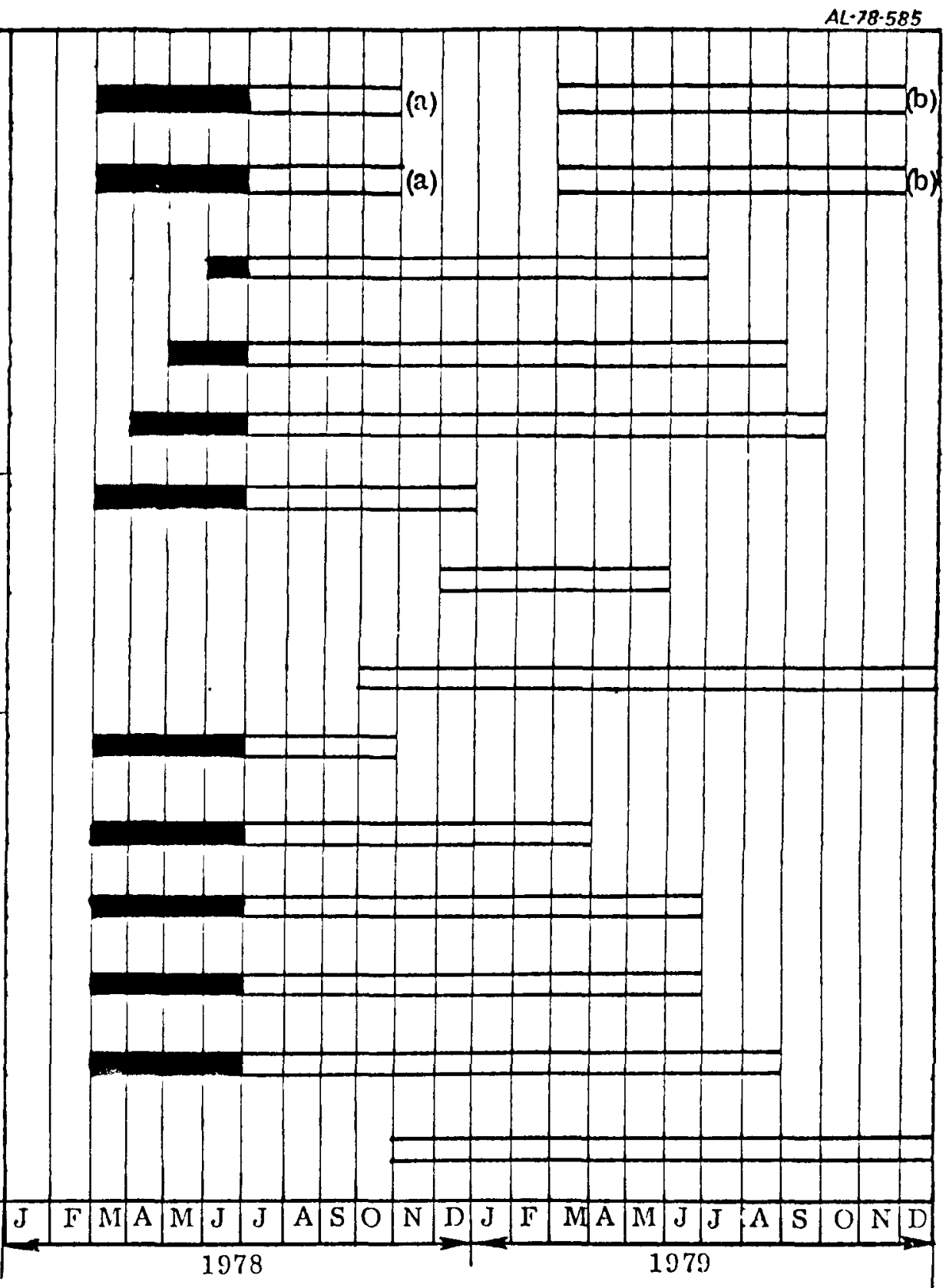

Figure 1. Timc-Phasing Chart for the Contract Morlification 
Task 3 - Modeling of Electrode Boundary Layer Plasma Dynamics

The decision was made to concentrate our initial efforts on the anode plasma sheath region. A hierarchy of models was outlined including: 1) A Phase One model to evaluate charge densities, the electric field and current; 2) A Phase Two model which includes negative ions with ambipolar diffusion and 3) A Phase Three model which includes finite rate chemical kinetics with possible vibrational excitation.

Work has been largely completed on a numerical code for solving the two-point boundary value problems with extraneous exponentially growing solutions which are characteristic of these models. Important cross sections have been tabulated, and a routine has been written to determine the integrated effect of these cross sections for interacting electron and neutral gases which have distinct temperatures and drift velocities. 
3. MODELING OF CORE FLOW PLASMA CHEMICAL EFFECTS ON CONDUCTIVITY AND SEED RECOVERY

\section{1 Goals and Milestones}

The primary objective of this task is the theoretical modeling of the MHD core flow to investigate the effects of:

(a) Condensed species, and

(b) Radiative heat losses

on the conductivity and hence the performance of the MHD channel. The results of this modeling effort will be integrated in the PACKAGE computer code. A preliminary description of this code is given by Kolb et al. ${ }^{(1)}$ The final version of the PACKAGE code will contain all the important effects that are modeled in this task. This task will also include experimental and theoretical efforts designed to study homogeneous condensation kinetics for slag vapors, in anticipation of adding a model for homogeneous slag condensation to the PACKAGE code.

\section{2 Summary of Improvements to PACKAGE Code}

The role of condensed species in capturing electrons has already been discussed by Kolb et al. (1) In coal-fired MHD systems a major source of condensed species is slag. Therefore, a first step in reducing the effects of condensed species is the removal of coal slag. The most practical place to remove the slag is in the combustor, where the combustion products have the lowest velocity. Due to high combustor temperatures required for seed ionization, the amount of nonvaporized slag in the combustor can be negligible. The two-stage combustor was developed to increase the amount of liquid slag retained in the combustor. In this system, coal is mixed with a fraction of the total oxidizer and burned in the first combustor. Being fuel-rich, the temperature of the combustion products in the first combustor can be low enough to contain large amounts of condensed 
slag, part of which can be rejected. The resulting slag-reduced mixture is then mixed with the remaining oxidizer and burned in the second combustor, resulting in high temperatures and ionization levels.

While equilibrium chemistry calculations suggest that the amount of condensed species will increase in the colder regions of the channel core, a more realistic model, accounting for the diffusion-controlled heterogeneous condensation and nucleation rate controlled homogeneous condensation, may result in a much lower generation of additional condensed species in the core of the channel. Therefore, the removal of the condensed species may result in a greatly reduced number of condensed particles along the channel, increasing its total efficiency.

Since removing slag prior to its entrance into the channel can be an important factor in the channel efficiency, in this reporting period we directed our efforts towards the modeling and programming of the two-stage combustor. To formulate this model we made the following assumptions:

- All the fuel is injected into the first combustor and a fraction $\alpha$ of all condensed species is removed from this combustor;

- A fraction $\beta$ of the total oxizidizer is injected into the second combustor and mixed with the slag-reduced combustion products of the first combustor;

- There is no heat loss from either combustor, therefore, in each combustor the enthalpy of the mixture before and after combustion is the same;

- The volume of condensed species is negligible with respect to the total volume available for the gaseous species. 
Given the enthalpy of reactants, oxidizer-to-fuel ratio, combustor pressure, and the concentration of the chemical elements of the system, the temperature and species mole fraction of the combustion products can be evaluated using equilibrium chemistry. Knowing $\beta, O / F$ (the total oxidizer-to-fuel ratio), pressure, and the enthalpy and amount of reactants used, the temperature and species concentration of the combustion products can be evaluated in the first combustor.

Let, in the first combustor, $n_{i}$ be the number of kilogram moles of $i$-th species per kilogram of mixture, $h_{0}$ the mixture enthalpy per kilogram of mixture and $b_{i}$ the number of kilogram moles of $i$-th chemical elements per kilogram of mixture. Using the conservation equations, we can show that after removing a fraction $\alpha$ of condensed species, the following relations hold:

$$
\begin{aligned}
& n_{i}^{\alpha}=\frac{n_{i}}{1-\alpha \sum_{i=m+1}^{n} n_{i} M_{i}} \quad i=1, \ldots, m \\
& n_{i}^{\alpha}=\frac{(1-\alpha) n_{i}}{n} \quad i=m+1, \ldots, n \\
& 1-\alpha \sum_{i=m+1}^{n} n_{i} M_{i}
\end{aligned} \quad \text { }
$$




$$
\begin{aligned}
h_{0}^{\alpha}(T)= & \frac{h_{0}-\alpha \sum_{i=m+1}^{n} n_{i} h_{i}(T)}{1-\alpha \sum_{i=m+1}^{n} n_{i} M_{i}} \\
b_{j}^{\alpha}= & \frac{b_{j}-\alpha \sum_{i=m+1}^{n} n_{i} a_{i j}}{1-\alpha \sum_{i=m+1}^{n} n_{i} M_{i}} \quad j=1, \ldots, l
\end{aligned}
$$

In these equations, indices $\mathbf{i}=1, \ldots, \mathrm{m}$ denote the gaseous species, while indices $i=m+1, \ldots, n$ denote the condensed species, $M_{i}$ is the molecular weight of the $i-$ th species, $a_{i j}$ is stoichiomet ric coefficient of the $j$-th element in the $i$-th species, $h_{i}(T)$ is the enthalpy per mole of the $i$-th species, $\ell$ is the number of chemical elements in the mixture, and superscript $\alpha$ defines a variable after removing $\alpha$ fraction of the condensed species.

Note that since the volume of the condensed species is negligible, their removal does not change the mixture temperature and pressure. Also note that given the pressure and Equations (3) and (4) equilibrium chemistry will predict the same temperature and $n_{i}^{\alpha}$ given by Equations (1) and (2).

Knowing $\boldsymbol{\beta}$, the fraction of oxidizer injected in the second combustor, and given $h_{0}^{\alpha}$ and $b_{j}^{\alpha}$, we can evaluate $h_{0}^{s}$ and $b_{j}^{s}$, which are the mixtu re enthalpy and kilogram moles of element $j$ per kilogram of mixture respectively, in the second combustor. These are given below: 


$$
\begin{aligned}
& h_{0}^{s}=\frac{[1+(1-\beta) O / F]\left[1-\alpha \sum_{j=m+1}^{n} n_{j} M_{j}\right] h_{o}^{\alpha}+O / F h_{o x}}{[1+(1-\beta) O / F]\left[1-\alpha \sum_{j=m+1}^{n} n_{j} M_{j}\right]+o / F} \\
& b_{j}^{s}=\frac{[1+(1-\beta) O / F]\left[1-\alpha \sum_{i=m+1}^{n} n_{i} M_{i}\right] b_{j}^{\alpha}+O / F b_{j o x}}{n} j=1, \ldots,
\end{aligned}
$$

wher $h_{\text {ox }}$ and $b_{j o x}$ are the oxidizer enthalpy and kilogram moles of $j$-th chemical element per kilogram of oxidizer. Given the pressure in the second combustor, and Equations (5) and (6), the temperature and species concentration of the combustion products can be evaluated for the second combustor using equilibrium chemistry.

The PACKAGE code has been modified to evaluate the mixture properties in the two combustors for any specified $\alpha$ and $\beta$.

\subsection{Work Forecast}

In the next reporting period, the effects of removing the condensed species on the homogeneous and heterogeneous condensation along the core of the channel will be investigated using finite rate kinetics. The important effects will be modeled and included in the PACKAGE.

A preliminary design of the slag condensation kinetics experiment will also be performed. 
Section 3 References

1. C. E. Kolb, et al., "Characterization of Open-Cycle, Coal-Fired MHD Generators, " Sixth Quarterly Report, Report No. ARI-RR-116, Aerodyne Research, Inc. (January, 1978). 


\section{LABORATORY MEASUREMENTS AND THE DESIGN OF A FIELD SCALE MASS SPECTROMETRIC PROBE}

\subsection{Goals and Milestones}

The Laboratory Measurements and Probe Design task includes three subtasks, Laboratory Burner Measurements, Field Facility Assessment, and Field Scale Probe Design. No work was scheduled on the last two sub-tasks during the period covered in this report. However, a decision was made to incorporate the construction of a model of a field scale probe sampler into the laboratory sampling and vacuum system redesign and rebuilding. This further links the Laboratory Burner and Probe Design sub-tasks. The benefits to both areas will be discussed below.

The laboratory program has two objectives, which are:

1. To support predictions of ope ration of full-scale MHD generators by supplying basic information on negative ion formation, and by providing data for model exercise and verification.

2. To test design concepts for a mass-spectrometric sampling device which would investigate coal ash effects on plasma conductivity in full-scale MHD generators.

The twofold objectives of the laboratory program can be justified in terms of the national MHD research program. First, because of the cost of constructing large test facilities, let alone full-scale MHD generating plants, many engineering decisions will have to be made on the basis of modeling predictions. In particular, the effect on plasma conductivity must be assessed of two processes due to the presence of coal slag in the MHD channel - negative ion formation and slag condensation. The first objective is to operate the coal burner and mass 
spectrometer to provide basic information which will allow the modeling of these processes. In particular the quantities desired are thermodynamic information on negative ions and their neutral precursors, the identity of molecules involved in slag condensation mechanisms, and perhaps some kinetic information, on the burning of coal particles to liberate negative ion precursors, or on slag vapor nucleation and condensation. This investigation not only involves coal flames where conditions are as close as possible to those in an MHD combustor, in which, for instance, the properties of various coal types can be studied, but also includes the use of clean, methane/air flames with accurately known amounts of seeding chemicals.

Still, even with careful and extensive modeling supported by laboratory burner measurements, eventually the two problems mentioned above must be investigated in full-scale MHD generator systems. The second objective is to learm, by sampling a well-characterized hot gas system, how to design a similar device which can sample from an MHD combustor or channel exit.

The achievement of these two general goals dictates several specific improvements to the laboratory burner and mass spectrometer system. For instance, variation of the burner temperature over as wide a range as possible is essential to obtain the thermodynamic information needed to predict ion concentrations not only at laboratory burner temperatures but also at MHD combustor temperatures. A burner modification which is a step in this direction is discussed below. With the new temperature capability, both qualitative and then quantitative data can be obtained on ion concentrations.

Another specific goal is the unambiguous identification of the coal ash ion species, by the introduction into the flame of gas or vapor compounds which will be ion precursors. After the se identifications have been made, quantitative data can be obtained on the ions of interest by adding known concentrations of these seeding compounds. A description of the design of the gas handling system for feeding these chemical now under construction, is given below. 
A third goal is the achievement in several ways of better characterization of the coal burner operating conditions. The concerns here include temperature measurement, first using more thermocouples to learn about temperature profiles across the burner flow, and eventually using sodium line reversal to measure temperatures above the range of platinum/rhodium thermocouples and to provide a check for lower temperatures. Another area of investigation is the constant ion background seen in clean flames. Although helpful in the past, it may now be necessary to clean the burner and suppress this background. A third, and very minor effort now underway, which will contribute to the better understanding of the burner is a theoretical burner model, starting with gas input flow rates and resulting in temperature and concentration profiles. This effort will involve no more than a few man-days aimed at verifying our previous understanding of the burner flow patterns.

\section{2 Technical Progress on Laboratory Measurements}

A major concern during the first phase of the experimental program was how tr. attain the high temperatures available using oxygen to augment the air/ methane flame without flashing back through the burner grid. Flashback became a problem when the entire burner was lined with fibrous zirconia whose superior insulating properties drastically cut heat losses from the gas by radiation and conduction. These new burner walls operated at temperatures very near the gas temperature, and when this same fibrous zirconia was used for the burner grids, they too would glow orange. When oxygen was added to the coal burner flame, increasing the flame speed, the grid was hot enough that it could not act as a flame arrestor, and flashback occurred. (The guard ring burner, which uses only gases, has a grid of porous stainless steel behind the zirconia which acts as an effective flame support.)

This situation has been greatly improved by the replacement of the lightweight fibrous zirconia burner grid by one made from a much heavier solid zirconia. Since the grid is mounted in a stainless steel tube which is in contact with water-cooled surfaces, the much better heat conductivity of the solid conductivity of the solid zirconia is enough to keep it quite cool. This has allowed operation with up to 20 percent oxygen fed through the center burner, 
resulting in exhaust gas temperatures measured by thermocouples directly in front of the sampling nozzle of as much as $2200^{\circ} \mathrm{K}$.

After a period of time in which the mass spectrometer was in use on another experiment, flame ionization observations were resumed. However, repetition of the observations made during the first phase of the program, let alone any new measurements, was made difficult by a series of mechanical failures of the sort that routinely plague electronic and vacuum systems.

The most serious of these, requiring over a month of repeated diagnosis and repair, was the appearance of large noise spikes on the signal output of the Channeltron particle multiplier. This problem was traced to high voltage leakage from a number of components of the triax feedthrough flange assembly, both inside and outside the vacuum system, as well as leakage across feedthroughs into the Channeltron housing. This leakage was ascribed to buildup of surface coatings during the time the system was not operated. For some components cleaning was sufficient, while others had to be replaced. In one case rough edges of a hole through the aluminum plate forming the triax flange housing had to be covered with a smooth bushing to prevent breakdown from the guard ring shield of the triax cable. These problems have been at least temporarily solved, and the signal output is once more quiet.

Once again, the observations of positive and negative ions have resumed. The background mass spectra observed from vaporized slag in the burner using a clean methane flame are of similar magnitude as observed in the last phase of work, and show all the same features. We have begun the addition of identifying chemicals to the flame by setting up a tank of phosphine $\left(\mathrm{PH}_{3}\right)$ to feed small amounts of phosphorous into the flame. This has resulted in further confirmation that the ions observed at mass 79 and 63 are indeed $\mathrm{PO}_{3}^{-}$and $\mathrm{PO}_{2}^{-}$, respectively. 
Other chemicals which have been obtained for identification purposes include carbonyl sulfide, boron trifluoride, methyl chloride and bromide, vinyl fluoride, trimethyl aluminum, and chromium, molybdenum, tungsten, and iron carbonyls. All these compounds have been chosen over more common chemicals in order that the ion precursors may be introduced into the flame in the gas phase. Not only is solid feeding and vaporization less reliable, but feeding solid particles can easily clog the sampling nozzle. Although the first five compounds listed and phosphine are permanent gases, all except carbonyl sulfide must be handled with considerable respect. The last five compounds are in condensed phases at room temperature, and must be warmed to obtained sufficient vapor pressure. For these reasons, a rather specialized gas handling system must be constructed, which we now proceed to briefly describe.

The intent is to produce sample cylinders containing mixtures of a small amount of seed gas with pressurizing nitrogen. With the permanent gases, these can be mixed immediately and bled through a calib rated metering valve Into the flame. The setting of this valve, and the flow rate as a function of sample cylinder pressure, will be determined initially using pure nitrogen and an auxiliary flowmeter. The sample gas will not contact the flowmeter for the same reasons that no pressure regulator is planned in place of the regulating valve. These are, that some of the gases planned can contaminate Burfaces, and more important, that the vapor species will condense out at room temperature, requiring that all lines and flow components be heated. The sample cylinders will reside in an oven, while tubing and valves leading to the burner will be wrapped with heating tape.

Finally, a design decision was made which should have considerable impact on both the laboratory measurement and probe design tasks. This is to construct for use with the laboratory burner a model of the field-scale probe sampling orifice assembly conceptually designed in the first phase of these studies. The design involves difficult problems in science (such as turning the flow, at rectuced pressure, out of the core flow into the mass spectrometer) and engineering, (such as keeping the sampling orifice open in a gas containing 
particles and slag and seed vapor). Therefore, operation on a well-characterized system to ensure that sampling is representative, as well as to uncover any mechanical problems, is necessary as part of the design task. In addition, a mechanism which can periodically clean out the sampling orifice without shutting down the burner or mass spectrometer will allow longer run times and mean more data collected from the laboratory burner.

\subsection{Work Forecast}

The plans discussed in the Goals and Milestones section can be divided into short-term and long-term objectives, with the qualitative study of negative ions and some of the burner characterization work coming under the former heading and most of the quantitative studies of ion concentrations as functions of temperature under the latter. We intend to attain those short-term objectives, to understand what ions are important at various temperatures and to better understand the burner conditions, in the next quarter. Also during the $\mathrm{nr} x \mathrm{t}$ three months we should finish construction of the seed gas handling syst $\in m$ and the sodium line reversal temperature measurement system, and begin operating them with the burner.

This operation of the burner alone will be particularly appropriate because extensive modifications of the vacuum system enclosing the mass spectrometer are also planned for this quarter, which will result in up to two months when mass spectrometric sampling of the burner will not be possible. The primary reason for these changes is to give the mass spectrometer the increased sensitivity required for the planned new negative ion and condensation experiments. A complete redesign of the vacuum system has been done, which should result in significant benefits to the MHD experiment. These benefits will include a better vacuum, and easier access to the mass spectrometer and ion optics train. This last point is particularly important, since these components often need servicing and the present arrangement results in much time being lost in each access. A secondary reason for planning these changes at this time is to allow another experiment to share the mass spectrometer. The time during which the vacuum system is being rebuilt will also be used to design and construct the model of the field-scale probe sampling section. 


\section{MODELING OF ELECTRODE BOUNDARY LAYER PLASMA DYNAMICS}

\section{1 Goals and Milestones}

The essential goal of this task is to investigate and characterize the physical phenomena which result in electrode erosion. In order to accomplish this goal, a series of models of successive complexity is planned. The primary focus of these models is the plasma sheath, since the significant electron acceleration that takes place in the sheath region probably results in the production of corrosive species.

The first phase model is designed to investigate the electric field, charge densities and current in the vicinity of the anode for diffuse discharge conditions. This model is described in Section 5.3, and is currently near completion. The results from the first phase model will be presented in the next quarterly report.

The next phase model will include negative ion effects, with ambipolar diffusion. This model should also be completed du ring the next quarter.

The third phase model will involve the introduction of finite rate chemistry. Several physical phenomena (nonequilibrium chemistry, elevated excited state populations, electron/neutral disequilibrium) will be considered. Progress on this model will be reported in the next qua rterly report.

Subsequent models will study the arcing boundary layer in an MHD channel. Surface effects become more important for this case, and they will be included. The current schedule calls for work on these models to commence around the second quarter of FY79. Intermediate results may, of course, alter the choice for subsequent models and their schedules.

Section 5.2 serves to place the present effort within the context of past efforts. Current technical progress is discussed in Section 5. 3, and the Work Forecast is presented in Section 5.4. 


\section{2 An Assessment of Past Work on MHD Plasma-Wall Interaction}

\subsubsection{Introduction}

Although early performance analyses for MHD generators were based on idealized uniform gas discharges, it was soon realized that the actual nature of the discharge in the electrode vicinity would not be quite so simple. There are a large number of effects tending to modify the current pattern, and some of them are now relatively well established and understood. First, even if one postulates the crudest possible plasma model (a perfectly uniform conducting medium), the presence of longitudinal segmentation in the electrode walls leads to current concentrations near the electrode-insulator edges. This well-known effect of boundary conditions on the solution of La Place's equation for the plasma potential is dramatically enhanced by the Hall effect, and leads to the characteristic and strongly asymmetric concentration of current at the downstream cathode edges and at the upstream anode edges. $(1,2)$ Local current densities can thus be several times higher than the average value, and wall design must account for t'is by providing sufficient local cooling and facilitating redistribution of current by electrode tailoring.

Also well known, although less perfectly quantified due to lack of simple analyses, is the effect of nonuniform conductivity associated with the relatively cool boundary layer near the wall. The combined effect of segmentation and boundary layer conductivity variations on the distribution of current was analyzed numerically by Oliver ${ }^{(3)}$, who also pointed out the further nonlinear concentration of current which results from plasma ohmic beating at the electrode edges. This can be regarded then as an early analysis of thermal constriction, and bears a resemblance to a model of the fully developed arc.

In further numerical studies, Oliver concent rated on a different, but related current concentration effect: that resulting from strong ohmic heating near the surface of an interelectrode insulator, which was shown to lead to an axial kind of arc between the electrode. This phenomenon is very destructive and its threshold is a definite bound on the operational map of an electrode wall. 
Interelectrode breakdown has been experimentally observed ${ }^{(4)}$ and further analyzed $(5,6)$, and generally good agreement is obtained between predicted and observed threshold voltages.

Aside from these current concentration effects, all of which are characterized by scales comparable to the electrode width, other smaller scale constrictions a re known to occur on the surface of electrodes under some conditions. These are generally termed "transverse arcs", although they bear only partial resemblance to the classical arc discharge (the column is almost totally absent). These arcs are at present much less well understood than the phenomena mentioned above, but some of their salient features are known, and will be summarized in what follows. An important point is that they are known to be destructive to the wall material, although not uniformly so, and not in all cases. Anode arcs a re particula rly damaging, both due to their generally higher current and possibly to chemical surface effects at their foot. Refractory ceramic electrodes suffer most from arcing, because their mobility subjects the material to co istant thermal shocking conditions. Strongly cooled copper electrodes suffer least, but show strong anodic oxidation unless protected. The importance of understanding the effects of arcs and the factors controlling their existence and properties is easily appreciated, mostly from the standpoint of ensuring long-term generator operation. The direct effects of arcing on performance are secondary (and may well be beneficial).

\section{2. 2 Experimental Studies of MHD Arcs}

A wealth of data exists on "classical" arcs in unseeded gases, and good summaries are provided by Ecker ${ }^{(7)}$ and Roman and Myers ${ }^{(8)}$. The former concentrates on the electrode effects from a theoretical viewpoint. The latter survey centers on the effects of cross flow and magnetic field. Both these surveys, then, contain information of some interest for MHD arcs (since they are essentially columnless arcs in a cross flow with magnetic field). The principal drawback from our standpoint is that only unseeded gases are considered, which leads to characteristically very high temperatures $\left(6000-20000^{\circ} \mathrm{K}\right)$, and therefore, quite possibly, to a different set of dominant effects than what may be 
expected in the easily ionizable $\mathrm{MHD}$ gas. Some more recent investigations of arcs in crossed fields $(9,10)$ tend to confirm the simplified model advanced in Ref. (8) for arc migration: the main flow does not penetrate the arc, which shows internal double cell recirculation, and the fluid dynamic pressure drop balances the Lorentz force. The picture is probably much less clear in "oneelectrode" arcs such as obtained on $\mathrm{MHD}$ electrodes. One other effect known from classical arcs and potentially important to MHD is the existence of " cold" electrode $\operatorname{arcs}^{(7)}$ which move rapidly on the electrode surface without any melting or sputtering, drawing many amps of current through tiny spots. The proposed "gaseous electrode" (11) concept seems to be based on this effect: magnetically rotated arcs in a cavity with argon flow can supply hundreds of amperes for hundreds of hours with little apparent wear; replacing argon with nitrogen eliminates this favorable mode of operation.

There are fewer experimental studies specifically aimed at MHD arcs, and most of them have been performed in the USSR. An exception is the work of Koste $r$ et al. ${ }^{(12)}$, which determined the voltage-current characteristics of potassium-seeded argon and obtained the cathode arcing threshold for a range of surface temperatures. Seed coverage of the surface was found to be a controlling effect.

Specifically aimed at seeded combustion gases is a series of investigations $(13-17)$ carried out at the Institute of High Temperatures in Moscow. The major findings are summarized below:

For copper electrodes, the anode voltage drop goes from $100 \mathrm{~V}$ at $400^{\circ} \mathrm{K}$ to $60 \mathrm{~V}$ at $1200^{\circ} \mathrm{K}$. The corresponding cathode drops are from $120 \mathrm{~V}$ to $100 \mathrm{~V}$. These voltages are still dominated by the ohmic component in the arc "funnel" through the boundary layer. Cathode microares first appear at about $0.15 \mathrm{~A} / \mathrm{cm}^{2}$; anode arcs appear at current densities from $0.4 \mathrm{amp} / \mathrm{cm}^{2}$, the threshold increasing linearly with substrate temperature. 
The apparent arc lifetime is 1-2 $\mathrm{msec}$ at low current, and increases to 6-10 msec at higher currents. The number of ares observed per electrode varies almost at random, but the statistical average converges to 2 arcs per electrode at the higher currents. Thus, the current per arc increases with total current. The arc diameter is also found to increase with current, but not enough to prevent the spot current density from increasing as well. The arcs do not subdivide upon reaching the same current level.

Application of a transverse magnetic field increases the arc motion by a factor of ten (from some 10 to $120 \mathrm{~cm} / \mathrm{sec}$ ) and the voltage drop in the preparation of $1+\beta^{2}(\boldsymbol{\beta}=$ Hall parameter $)$, but does not affect the number of arcs. At higher surface temperatures, the spots are wider, and the voltage drop is less.

The arc erosion rate is found to be about $1 \mu \mathrm{g} /$ coul. or less for copper, but some $10 \mu \mathrm{g} /$ coul. for iron electrodes. Gas temperature measurements in the vicinity of the spot gave values extrapolating to a round $7000^{\circ} \mathrm{K}$. The deposited layer of seed seemed essential to the discharge. The transient arc impedance was r leasured and is mostly inductive.

Some more light is shed on the effect of molecular gases on arcs by the results reported in Ref. (18). In pure seeded argon, the observed arcs on copper electrodes were large and luminous, with only one per electrode, centered on it. Its frequency of pulsation dec reased at higher current. The erosion rate increased linearly with current and exponentially with surface temperature. However, with addition of small amounts of oxygen, the arcs tended to carry about 5-6 amperes each, and subdivided when the current reached this level. The pulsations were at $500 \mathrm{kHz}$, independently of current, and the erosion rate was independent of both current and surface temperature. The arcs now tended to attach at the electrode edges and to have a constant voltage drop of $12 \mathrm{~V}$ (in pure argon, $\Delta \mathrm{V}$ increased from $12 \mathrm{~V}$ as the current increased).

The connection between arcing on the electrode and interelectrode breakdown is explored in Ref. (4). An important finding is the definite increase in near-wall electrical fluctuations as the breakdown threshold is approached. 


\section{2. 3 Modeling of Diffuse and Arcing Discharges}

Many analytical efforts were made on the classical arc discharges, and most of them are catalogued in Ref. (7). The more successful analysis dealt with the arc column, an almost nonexistent feature in MHD arcs. The analysis of the electrode regions posed serious difficulties, especially regarding the source of the extreme current densities observed at cathode spots. Ecker ${ }^{(7)}$ combined the classical mechanisms of thermionic emission and field emission with the concept of individual ion field emission, and succeeded in explaining a wide range of nonlinear arc phenomena. His analysis includes matching of the near-electrode regions to a "funnel" which is dominated by bulk plasma effects and connects in turn with the column. Very careful consideration of the transport properties in this region was made by Lee ${ }^{(19)}$, who extended Ecker's models. Several aspects of the cathode region were analyzed in a series of papers by Beilis and associates $(20,21,22)$.

A fairly comprehensive formulation of the equations governing an arc in coml ustion, seeded MHD gas was made by Adams and Robinson ${ }^{(23)}$. Equilibrium chemistry was assumed, except for charged species; the "funnel" shape was arbitra rily taken as conical and no magnetic field was assumed. The equations were thus reduced to one-dimensional form, and matching of currents at various interfaces imposed by trial and error. A minimum voltage principle with only heuristic validity was invoked in order to close the set of equations. One conclusion was that spot temperatures need not exceed the melting point of the wall material (in some contradiction to observations of Ref. (17)). In Ref. (24), an analysis is made of the rate of travel of an arc spot on an electrode, based on the rate of evaporation of a layer of deposited seed. Other arc features, such as diameter and spot temperature are calculated from relatively simple models and compared to data from Refs. (13-17).

Other models similar in nature to those of (24) or (23) were also presented by Mueblhauser and Dicks ${ }^{(25)}$ and Hsu ${ }^{(26)}$. 
In essence, the great geometrical and physical complexity of the arc region forces all of the above models to resort to various assumptions and approximations in order to reduce the mathematical appratus needed. By contrast, more sophisticated analysis of the conditions in a diffuse discharge is possible. Typical of these is the work of Okazaki et al., who, in two recent papers ${ }^{(27,28)}$ analyze current-carrying boundary layer, lonizing segmentation, but including electron nonequilibrium and sheath effects, as well as the fluid transport equations for the boundary layer. Their second paper is a careful perturbation analysis about the profile derived in the first one; perturbations are assumed independent of the direction along $\vec{B}$, which may not be a serious restriction. The stability curve marking the onset of an electrothermal instability is thus computed for various conditions, and the result may have a bearing on the onset of arcing, at least on anodes, where surface conditions are less dominant. Similar electrothermal constriction analyses had been reported by Oliver ${ }^{(29)}$. The effects of a partial layer of metallic seed on a high work function electrode was investigated in the diffuse discharge model of Koster et al. $;^{(12)}$ of course, metallic alkali deposits are not possible in combustion gas environments.

\section{2.4 Discussion of Previous Models}

As noted, the arcing models used so far have been severely limited by the complexity of the problem. Most of them have almost completely ignored nonequilib rium chemical effects, such as molecular excitation and dissociation, rate-controlled negative ion formation, wall chemistry and seed condensation or chemical transformation. They have also generally relied on crude approximations as to the funnel geometry, the complexity of which can be appreciated by a glance at the isotherms measured in Ref. (17), or by consideration of the flow speeds prevalent very near the electrode surface. A common limitation has been the neglect of unsteady effects, despite repeated observations of rapid fluctuations at the spots. Some of the above criticism must also extend to the existing models of diffuse discharges, especially as regards chemical effects. These must be very important, both in determining the electrical properties of the gas, and in their own right, since chemically reactive species are probably liberated in the 
vicinity of the electrode surfaces, and accelerated erosion can then be expected. The common observations on anode oxidation rate testify to this.

The limitation to a steady state model seems indeed difficult to remove with the present computational capabilities. The inclusion of more adequate chemical models is only a question of some effort, since the relevant rates and cross sections have been generated at increasing rates, mostly under the stimulus of high power laser research. ${ }^{(30)}$ An example of careful modeling of molecular effects is the closed cycle contaminant work of G. E. ${ }^{(31)}$ Some improvement is also possible in the area of three dimensional arc effects by employing finite element or similarly flexible numerical techniques. At a minimum, some of the arbitrariness in the zonal subdivision of the arc, which is a feature of all the earlier models, can be removed. Finally, a necessary improvement is a consideration of the surface physics and chemistry, especially for ceramic or slagged electrodes.

\subsection{Oechnical Progress of Model Development}

Our initial literature search on the topic of arcing and spot phenomena in electrode-plasma boundary layers revealed that anode phenomena, especially with regard to chemistry, have not been thoroughly studied. In particular, there has not been a satisfactory model for the process of anode erosion. Because of the severe limitation that anode erosion poses to MHD generators and also because the complicated surface phenomena of the cathode may be avoided, we chose to direct our initial efforts towards modeling the electrodynamics and chemistry of the anode boundary layer.

We reviewed literature concerning the cross sections for inelastic processes involving electrons and found that electronic excitation and deexcitation of seed (for example, potassium) atoms and excitation/de-excttation of the vibrational modes of $\mathrm{CO}_{2}, \mathrm{H}_{2} \mathrm{O}, \mathrm{CO}$, and $\mathrm{N}_{2}$ will be significant in determining the electrons energy balance. Two important questions arise: 
(1) Do any of the vibrational modes become excited?

(2) Do the electrons maintain a Boltzmann distribution?

The first question arises because the boundary layer is characterized by a steep temperature gradient between the cool electrode and the hot core. The electrons streaming to the electrode experience Joule heating and are able to maintain an elevated temperature compared to the background gas. Depending on how closely the vibrational modes are coupled to the electrons and to the gas via inelastic collisions, the vibrational temperatures may remain unignited (i. e., equal to the background gas temperature) or ignite (i. e., elevate somewhat due to the influence of the electrons). The effect of this is that as the vibrational temperature approaches the electron temperature there will be less energy transferred from the electrons to the vibrational modes. A rough calculation showed that there is some possibility of the $\nu_{3}$ mode of $\mathrm{CO}_{2}$ (which is strongly coupled to the first vibrational state of $\mathrm{N}_{2}$ ) becoming excited, but that for a first attempt this effect may be ignored.

The question concerning the electron distribution is important because it is the high energy tail of the distribution which is capable of producing oxidizing agents near the electrode. Some of the inelastic cross sections contain sharp peaks at energies of a few electron volts which Nigham ${ }^{(32)}$ showed may have the effect of depleting the high energy tail. For a first attempt in our Phase Three model, we will initially use a translating Maxwellian distribution and come back to this potentially important effect.

We next looked at the effects of the extremely steep temperature gradient, on the order of $1000^{\circ} \mathrm{K}$ per millimeter. We used the NASA-CEC code to calculate equilibrium concentration for species of a typical combustion mixture. Assuming that chemical equilibrium is maintained in the thermal gradient, we calculated the necessary production rates for species important in governing the avallabllity of electrons and some oxidizing agents. Using reaction rates from Jensen and Jones ${ }^{(33)}$, we found that many of the reactions cannot proceed rapidly enough to maintain equilbrium. Therefore we concluded that in order 
to model anode erosion, it is necessary to include finite rate chemical kinetics.

We have started modeling the diffuse discharge as a precursor to the constricted discharge in order to familiarize ourselves with the phenomena and to arrive at background conditions surrounding the arc. A one-dimensional model is being developed which takes into account continuity of species with finite rate chemistry, momentum of each species as diffusion through a background mass flow, and energy of the electrons and gas separately. A code has been programmed and tested for solving a system of first order nonlinear differential equations using a quasilinearization technique with an implicit integration subroutine. Before attempting the complete diffuse model, this code will be used first on our Phase One model, which includes a set of four equations:

(1) Electron continuity,

(2) Ion momentum,

(3) Electron momentum, and

(4) Poisson equations.

Thus, it can examine the densities, field, and currents in the space charge sheath and the ambipolar diffusion region. Next, charge neutrality will be assumed, negative ions will be introduced, and energy equations will be included to calculate the electron and gas temperature distributions.

\subsection{Work Forecast}

Work on the Phase One model is near completion, with problems due to extraneous exponentially growing solutions apparently solved. It is expected that this model as well as the Phase Two model (including negative ion effects with ambipolar diffusion) will be completed during the next quarter. Progress towards the more complicated Phase Three model should also be reported in the next quarterly report, as a prelude to consideration of the more difficult arcing problem which is to follow. 


\section{Section 5 References}

1. Hurwitz, H., Jr., Kilb, R.W., and Sutton, G.W., "Influence of Tensor Conductivity on Current Distribution in an MHD Generator, " J. Appl. Phys., 32 205 (1961).

2. Dzung, L.S., "Favorable Configurations of Segmented Electrodes for MHD Generators," Brown Boveri Review, 55, No. 3, p. 238 (1966).

3. Oliver, D.A. and Mitchner, M., "Nonuniform Electrical Conduction in MHD Channels," ALAA (Aug., 1967).

4. Kovbasznk, V.N., Baranov, N.N., Zserov, A.D., and Klimovsky, J.J., "Creation of Interelectrode Arcs and Electric Fluctuations in MHD Channels, "17th Symposium on Engineering Aspects of MHD, Stanford (1975).

5. Unkel, W.C., "Axial Field Limitations in MHD Generators," Topical Report DOE FE-2341-8, Distribution category UC-90G, (April 1978). Also $\mathrm{Ph}$.D. thesis, Stanford University, (1978).

6. Russo, A.J., Blottner, F.G., and Touryan, K.J., "Transient Behavior of the Fluid and Electrical Properties in the Turbulent Boundary Layer of an MHD Channel, " 17th Symposium on Engineering Aspects of MHD, Stanford University (1978).

7. Ecker, G., "Electrode Components of the Arc Discharge," Ergebnisse der Exackten Naturwissenschaften, Vol. 33 (1961) (645 Reference).

8. Myers, T.W. and Roman, W.C., "Survey of Investigations of Electric Arc Interactions with Magnetic and Aerodynamic Fields, "USAF Aerospace Research Laboratories, Report No. 66-0184 (1966).

9. Winograd, Y.Y. and Klein, J.F., "Electric Arc Stabilization in Crossed Convective and Magnetic Fields," ALAA J., Vol. 7, No. 9, (Sept. 1969).

10. Droult, M.G., Beaudet, R., and Jutras, R., "Anode Current Distribution in a Moving Arc," AIAA J., Vol. 13, No. 7 (July 1975).

11. Scannel, E.P., Dooley, M.T., Hiers, R.S., Staats, G.E., and Bradley, N.A., Reynolds Metal Co., 16th Symposium on Engineering Aspects of MHD, Pittsburgh, Penn., (1977).

12. Koster, J.K., Sajben, M., and Zuboski, E., "Analytical and Experimental Studies of Thermionically Emitting Electrodes in Contact with Dense Seeded Plasmas," 11th Symposium on Engineering Aspects of MHD (1970). 
References (Cont.)

13. Felkson, Yu M., Kirillov, V.V., Reshetkov, E.P., and Flid, B.D. "Laws Governing the Operation of the Metallic Electrodes of an MHD Generator," Teplofiz. Vys. Temp., Vol. 8, No. 1, pp. 193-202 (Jan. - Feb. 1970).

14. Zalkind, V.I., Kirillov, V.V., Larionov, Yu A., and Semenov, N.S., "The Microarc Operating Regime of MHD Generator Electrode," Zhurnal Prikladnoi Mek, i Tek, Fiz., Vol. 11, No. 1, pp. 130-134 (Jan. - Feb. 1970).

15. Zalkind, V.I., Kirillov, V.V., Markina, A.P., Trikhotskii, A.S., and Uspenskaya, G. L., "Experimental Investigation of Cathode Spots on Metallic Electrode Protruding in Plasma Flow," Prikl. Mek. i Tekh. Fiz., No. 2, pp. 17-23 (March - April 1974).

16. Baranov, N.N., Molotkov, V.I., Poberezsky, L.P., Beilis, I.I., Zalkind, V.I., Zekzer, M.P., Tikhotskii, A.A., "Investigation of Physical Processes in the Near-Electrode Region of MHD Generators," 15th Symposium on Engineering Aspects of MHD, Philadelphia, Penn.(1976).

17. Vasli'yev, N.N. Grincheko, B.M., Zykova, N.M., Jsayenkov, Yu, I., Tinrakina, T.S., Lukash, V.E. , Nedospasov, A.V., Pobereszky, L.P., and Puzdryev, M.I., "Some Parameters of Near-Electrode Arc Processes in an MHD Generator," Proc. of the 6th International Conference on MHD Electrical Power Generation, Washington, D.C. (1975).

18. Chelskin, E.K., Gribkov, V.M., Jimerin, D.G., Motulevich, V.P., "Properties of Nonstationary Cathode Spots on the Surface of Cooled Electrodes, "Proc. of the 14th Symposium on Engineering Aspects of MHD, Paper III. 3 (1974).

19. Lee, T.H., Physics and Engineering of High Power Switching Devices, MIT Press, Cambridge, Mass. (1975).

20. Beilis, I.I. Rakhovskii, V.I., "Theory of the Cathode Mechanism of an Arc Discharge," Teplafizika Vysokikh Temp., Vol. 7, No. 4, pp. 620-625, (July - Aug. 1969).

21. Lynbrimov, G.A., "Cathode Region of a High Current Arc," Sov. Phys.Tech. Phys., Vol. 18, No. 4, (Oct. 1973).

22. Beilis, I.I. and Lyubinov, G.A., "Theory of the Arc Spot on a Film Cathode," Zh. Tekh. Fiz., 46, 1231-1239 (June 1976). 
References (Cont.)

23. Adams, R.C. and Robinson, E., "Electrode Processes in MHD Generators," Proceedings of the IEEE, Vol. 56, No. 9, (Sept. 1968).

24. Beilis, I.I., Zalkind, V.I., and Tikhotkii, A.S., "Cathode Spots on Metallic Electrodes Under the Conditions of the Channel of an MHD Generator," Teplofiz. Vys. Temp., Vol. 15, No. 1, pp. 158-162, (Jan. - Feb. 1977).

25. Muehlhauser, J.W. and Dicks, J.B., "Arc Spots and Voltage Losses in a Hall Generator," Proc. of the 14th Symposium on Engineering Aspects of MHD, Paper VIII. 2 (1974).

26. Hsu, M.S.S., "Thermal Instabilities and Arcs in the MHD Boundary Layers," Proc. of the 13th Symposium on Engineering Aspects of MHD (1973).

27. Okazaki, K., Mari, Y., Ohtake, K., and Hijikata, K., "Analysis of the Seeded Combustion Gas Boundary Layer Near a Cold Electrode, " AIAA J., Vol. 15, No. 12, pp. 1778-1784, (Dec. 1977).

28. Okazaki, K., Mari, Y., Ohtake, K., and Hijikata, K., "Electrothermal Instability in the Seeded Combustion Gas Boundary Layer Near Cold Electrodes," ALAA J., Vol. 16, No. 4, pp. 334-339 (April 1978).

29. Oliver, D.A., "A Constricted Discharge in MHD Plasma," 15th Symposium on Engineering Aspects of MHD, Philadelphia, Penn. (1976).

30. Principles of Laser Physics, George Bekefi, ed., J. Wiley \& Sons (1976).

31. Dellinger, T.C. and Gray, E.L., "Kinetic Model for Molecular Contaminant Effects in Closed Cyle, Nonequilibrium MHD Generators, "17th Symposium on Engineering Aspects of MHD (1978).

32. Nigham, W.L., "Electron Energy Distribution and Collision Rates in Electrically Excited $\mathrm{N}_{2}, \mathrm{CO}$ and $\mathrm{CO}_{2}, "$ Phys. Rev. A., Vol. 2, No. 5, (1970).

33. Jensen, D.E. and Jones, G.A., "Reaction Rate Coefficients for Flame Calculations," Combustion and Flame, 32, 1 - 34 (1978). 